\title{
A new quantitative reverse phase high-performance liquid chromatographic method for the quantification of Rilpivirine hydrochloride in bulk and dosage form
}

\author{
Sonam Patel, Krishnaveni Nagappan*, Gouru Santhosh Reddy \\ Department of Pharmaceutical Analysis, JSS College of Pharmacy (A Constituent College-JSS Academy of Higher Education \& Research, Mysuru), \\ Udhagamandalam, India.
}

\begin{tabular}{l}
\hline ARTICLE INFO \\
\hline Received on: $14 / 05 / 2018$ \\
Accepted on: $11 / 10 / 2018$ \\
Available online: $30 / 11 / 2018$
\end{tabular}

\section{Key words:}

Rilpivirine hydrochloride, RP-HPLC, Method

optimization, Method

validation

\begin{abstract}
Objective: The aim of this present study is to develop a precise, accurate, and linear reverse-phase high-performance liquid chromatographic (RP-HPLC) method for the assessment of Rilpivirine hydrochloride in the pharmaceutical dosage form.

Methods: The chromatographic system employs a reverse phase shim-pack $\mathrm{C}_{18}$ column $(150 \times 4.6 \mathrm{~mm} ; 5 \mu)$ using the mobile phase acetonitrile: ammonium acetate buffer $(0.05 \mathrm{M})(\mathrm{pH}-3.5$ equalized with glacial acetic acid) in the proportion of $60: 40 \mathrm{v} / \mathrm{v}$, delivered at a flow rate of $0.8 \mathrm{ml} /$ minutes with the detection wavelength of $291 \mathrm{~nm}$.

Results: The developed method resulted in retention of Rilpivirine hydrochloride at 4.5 minutes. Rilpivirine hydrochloride exhibited a linear relationship $\left(r^{2}>0.999\right)$ over the analytical range of $5-50 \mu \mathrm{g} / \mathrm{ml}$. The precision is represented by a relative standard deviation of $0.709 \%$. The percentage recovery was observed in the range of $98 \%-102 \%$, indicating the accuracy of the study. The detection limit and quantification limit were found to be 0.104 and $0.315 \mu \mathrm{g} / \mathrm{ml}$, respectively.

Conclusion: A precise, accurate, rapid, and linear RP-HPLC method has been developed and validated for the quantification of Rilpivirine hydrochloride in bulk and in tablet formulation $(25 \mathrm{mg})$ as per ICH Q2A ( $\left.{ }^{2}\right)$ guidelines. The developed and validated method can further be used for routine analysis of Rilpivirine hydrochloride in various pharmaceutical industries.
\end{abstract}

\section{INTRODUCTION}

Highly active antiretroviral therapy (HAART) has brought a new hope for those people who are suffering from HIV/AIDS by decreasing the death rate among people infected with HIV. HAART enhanced the quality of life among the people suffering from HIV/AIDS (AIDS Epidemic, 2009).

Rilpivirine $\mathrm{HCl}$, a second-generation non-nucleoside reverse transcriptase inhibitor (NNRTI) is commonly used for

\section{${ }^{*}$ Corresponding Author}

Krishnaveni Nagappan, Department of Pharmaceutical Analysis, JSS College of Pharmacy (A Constituent College-JSS Academy of Higher Education \& Research, Mysuru), Udhagamandalam, India.

E-mail: krisath@gmail.com; krisath@jssuni.edu.in the treatment of HIV infection in humans. It is highly potent with minimum side effects when compared with other NNRTIs. Due to the flexibility of interactions with HIV-III, they had demonstrated the activity against NNRTI resistant viral strains (Schrijversa et al., 2011; Sharma et al., 2013).

Rilpivirine, chemically denoted as 4-\{[4-(\{4-[(1E)2-Cyanoethenyl]-2, 6 dimethylphenyl $\}$ amino)-2 pyrimidinyl] amino benzonitrile with a molecular formula of $\mathrm{C}_{22} \mathrm{H}_{18} \mathrm{~N}_{6}$. It is mainly used to treat HIV-1 infection in combination with other antiretroviral agents (Fig. 1) (Lieven et al., 2009).

A detailed literature survey indicated few analytical methods for the quantification of Rilpivirine hydrochloride individually and in combination with other drugs using various analytical techniques.

Sarkar et al. have reported an RP HPLC and UV spectrophotometric method for the quantification of antiretroviral 


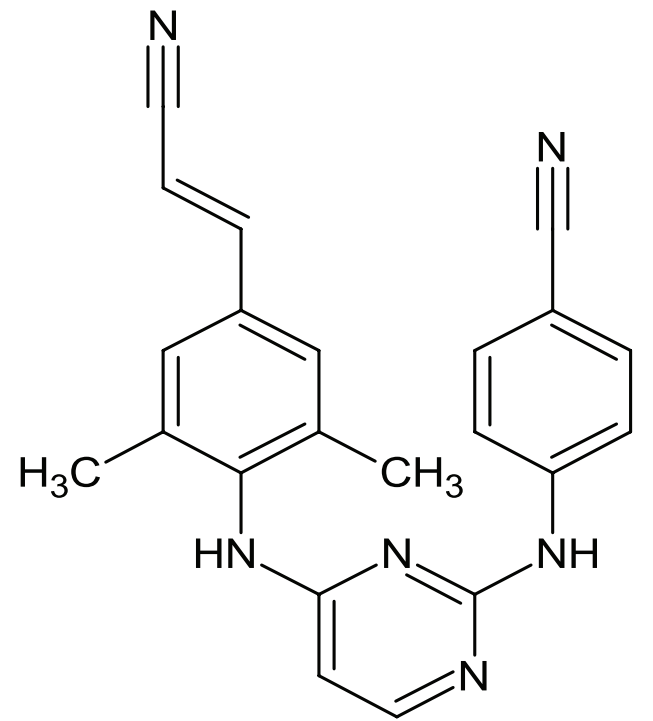

Figure 1. Chemical structure of Rilpivirine hydrochloride.

drugs lamivudine, stavudine, and nevirapine in API and also in pharmaceutical formulations. The method was validated as per ICH Q2 guidelines (Sarkar et al., 2006). Marineni et al. have reported a stability indicating HPLC method for the determination of Rilpivirine hydrochloride using a Gemini phenomenex $\mathrm{C}_{18}$ column $(250 \times 4.6 \mathrm{~mm}, 5 \mu)$ and mobile phase containing $15 \mathrm{mM}$ potassium dihydrogen phosphate buffer $\left(\mathrm{pH} 3\right.$, adjust with $\left.\mathrm{H}_{3} \mathrm{PO}_{4}\right)$ and methanol in gradient mode (Marineni et al., 2013).

Madhuri et al. (2015) had reported an RP-HPLC method for the quantification of Rilpivirine hydrochloride in nanosuspension using base deactivated silica hypersil column and methanol: acetonitrile: water $(80: 13.5: 6.5) \mathrm{v} / \mathrm{v}$ as mobile phase (Madhuri et al., 2015). Venkatesh et al. (2004) had reported a reverse phase-LC method for simultaneous quantification of three drugs viz., emtricitabine, tenofovir disoproxil, and rilpivirine $\mathrm{HCl}$ in tablet dosage form. Kavitha et al. (2013) had reported an RPultra performance LC method for quantification of emtricitabine, tenofovir disoproxil, and Rilpivirine in tablet dosage form. Reddiah et al. had reported an RP-HPLC method for the quantitation of Rilpivirine hydrochloride during its in vitro dissolution study. The mobile phase used was ammonium acetate buffer $(\mathrm{pH} 4)$ and acetonitrile in isocratic mode (Reddiah et al., 2012). (Fathima et al., 2018) had reported a reverse phase-high-performance LC method for the quantification of Rilpivirine hydrochloride among their degradation products by using mobile phase potassium dihydrogen phosphate $(\mathrm{pH} 3)$ and methanol in gradient mode. (fathima et al., 2018) Devanoboyina et al. had reported an LC method for quantification of Rilpivirine hydrochloride in bulk and pharmaceutical formulations using a $\mathrm{C}_{18}$ column and mobile phase composition consisting of orthophosphoric acid buffer ( $\mathrm{pH} \mathrm{2.5)} \mathrm{and} \mathrm{acetonitrile} \mathrm{50:50 \%} \mathrm{v/v.} \mathrm{The} \mathrm{flow} \mathrm{rate} \mathrm{was} 1.2 \mathrm{ml} /$ minutes (Devanoboyina et al., 2014).

From the literature survey, it was evident that most of the methods were utilizing phosphate buffer for the quantification of Rilpivirine. Thus, the present study aims to develop and validate a simple, rapid, precise, accurate, highly sensitive, and selective RP HPLC method which is compatible for LC-MS/MS and can be routinely used for quality control studies. The method showed

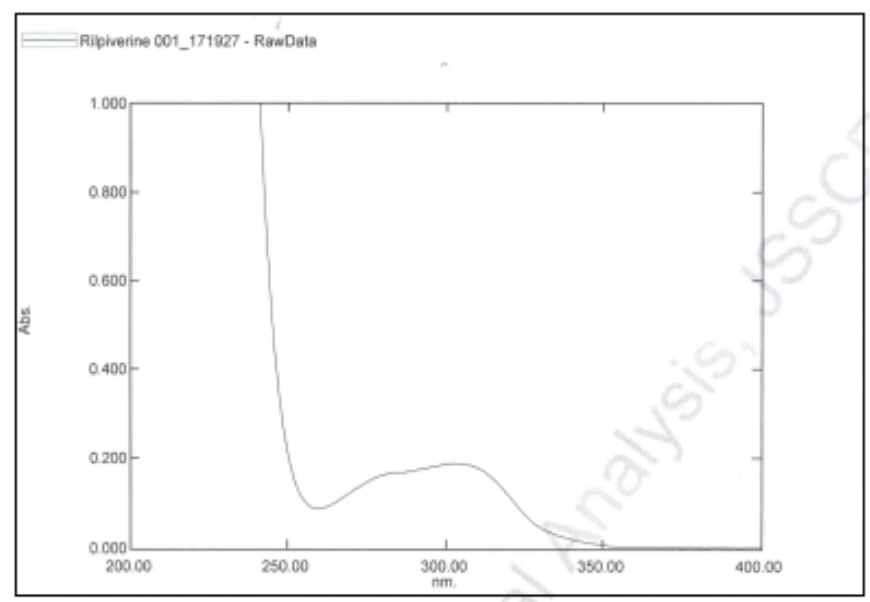

Figure 2. UV spectra of Rilpivirine hydrochloride.

a recovery of $98 \%-102 \%$ with a simple mobile phase composition of ammonium acetate buffer ( $\mathrm{pH} 3.5)$ and acetonitrile (40:60 v/v) in isocratic mode with shimpack $\mathrm{C}_{18}$ column. This developed method is robust enough to transfer into LC-MS/MS and HR/MS characterization for the determination of Rilpivirine hydrochloride in bulk and pharmaceutical formulations.

The validation of the developed RP HPLC was performed as per the ICH guidelines (Bakshi et al., 2002; ICH Q2 (R1), 2005).

\section{MATERIALS AND METHODS}

\section{Chemicals}

Acetonitrile HPLC grade, methanol, and ammonium acetate AR grade were procured from Merck (Mumbai, India). Milli Q water purification system (Bangalore, India) was used to generate Water HPLC grade. Reference substance of Rilpivirine (API) was obtained from Mylan laboratory, Hyderabad, India as a gift sample. The Rilpivirine formulation was procured from the local market.

\section{Instrumentation}

HPLC experiments were performed on a Shimadzu LC-2010A Autosampler (Shimadzu Corporation, Kyoto, Japan). The system was equipped with a liquid chromatograph system comprising LC-2010A quaternary low pressure mixing pump, Shimadzu SPD-20A UV-VISIBLE detector, a shim pack RP$\mathrm{C}_{18}$ column $(150 \times 4.6 \mathrm{~mm} ; 5 \mu)$ and an autosampler with $20 \mu \mathrm{l}$ aliquots sample loop volume. The software for data collection and analysis in the HPLC system used was Class VP data station. The UV spectra were recorded using the Shimadzu 1700 (E) spectrometer.

\section{Selection of wavelength}

A standard solution of $1 \mathrm{mg} / \mathrm{ml}$ Rilpivirine hydrochloride was prepared in methanol. From the above stock solution, 10 $\mu \mathrm{g} / \mathrm{ml}$ solution was prepared with the mobile phase and the UV spectra were recorded by scanning the standard solution between 200 and $400 \mathrm{~nm}$. Rilpivirine hydrochloride showed maximum absorbance at $291 \mathrm{~nm}$ (Fig. 2), thus, it was selected for monitoring the chromatographic eluents using a UV detector. 


\section{Standard and sample solutions preparation}

Primary standards of Rilpivirine hydrochloride were prepared by dissolving $10 \mathrm{mg}$ of Rilpivirine hydrochloride with a mobile phase in a $10-\mathrm{ml}$ volumetric flask $(1 \mathrm{mg} / \mathrm{ml})$. From the above standard stock solution, series of dilutions viz., 100, 10, and $1 \mu \mathrm{g} / \mathrm{ml}$ were prepared in the mobile phase and was used as $100 \%$ target concentration.

\section{Assay of the marketed formulations}

A quantity of 10 tablets was accurately weighed and finely powdered. Weight equivalent to $40 \mathrm{mg}$ of Rilpivirine hydrochloride was weighed and transferred to a $100-\mathrm{ml}$ volumetric flask. About $75 \mathrm{ml}$ of mobile phase was added, sonicated for 10 minutes, filtered using $0.45 \mu$ nylon membrane, and the volume was adjusted to $100 \mathrm{ml}$ with the mobile phase (Solution A). The Solution A was further diluted to obtain a working standard containing $40 \mu \mathrm{g} / \mathrm{ml}$. This was analyzed in triplicate using the optimized chromatographic, conditions the chromatograms were recorded and the amount present, standard deviation, and \% RSD were calculated and reported.

\section{METHOD VALIDATION}

The developed RP HPLC method for the quantification of Rilpivirine hydrochloride was validated as per the ICH Guidelines for the following parameters: specificity, linearity, precision and accuracy, detection limit and quantification limits, robustness, and ruggedness.

\section{Specificity}

Specificity is the ability of the method to measure the analytes response in the presence of other excipients and potential impurities. The specificity was demonstrated by comparing the chromatogram of drug extracted from the tablet with that of standard solution for the presence of excipients, potential impurities, and other degradants. No interference was observed in the sample solution at the retention time of Rilpivirine hydrochloride.

\section{Linearity and range}

The linearity of an analytical method indicates the response obtained which is linearly proportional to the concentration of the analytes in definite range. The linearity of the proposed method was evaluated over a range of 5-50 $\mu \mathrm{g} / \mathrm{ml}$. These working standards were prepared in mobile phase from $1 \mathrm{mg} / \mathrm{ml}$ standard stock solution. The working standards for the linearity were injected in triplicate under the optimized chromatographic conditions and the chromatograms were recorded. The linearity was established based on the correlation coefficient obtained by plotting a graph with concentration $(\mathrm{Mcg} / \mathrm{ml})$ in $x$-axis and area of Rilpivirine hydrochloride in $y$-axis.

\section{Precision and accuracy studies}

The method precision was evaluated by intraday and intraday precision studies. Six independent injections of three different concentrations viz., 3, 13, and $45 \mu \mathrm{g} / \mathrm{ml}$ (LQC, MQC, and HQC levels) were used to study the method precision. Intraday precision/repeatability was carried out by injecting the above samples on the same day and interday precision was carried out by injecting the same samples on three different days. The mean and values of $\%$ relative standard deviation were calculated.

The accuracy of the method was reported as recovery studies. It was carried out by standard addition method, i.e., by the addition of known concentration of standard drug to the real sample and analysis by the optimized chromatographic condition. The recovery experiments were studied at three different levels (3, 13 , and $45 \mu \mathrm{g} / \mathrm{ml}$ ) and the $\%$ mean recovery, standard deviation, and $\%$ relative standard deviation were calculated.

\section{Limit of detection and limit of quantification}

A method is considered sensitive when it is capable of detecting low concentration of the analyte. Detection limit (LOD) and quantification limit (LOQ) were determined by analyzing the low concentration of the standard solution using the developed RP HPLC method. The LOD is the smallest concentration of the analyte that gives a measurable response (signal-to-noise ratio $3)$. The LOQ is the smallest concentration of the analyte which gives a response that can be accurately quantified (signal-to-noise ratio 10). LOD and LOQ value can be measured by the following formula:

$$
\mathrm{LOD}=3.3 \sigma / S \text { and } \mathrm{LOQ}=10 \sigma / S
$$

where $\sigma=$ standard deviation of the response; $S=$ slope of the deviation curve.

\section{Robustness and ruggedness}

The ruggedness and robustness of the methods were studied by making slight changes in the experimental conditions (analyst, reagent source, and columns of various brands) and optimized chromatographic conditions ( $\mathrm{pH}$, mobile phase composition, and mobile phase ratio and flow rate).

\section{System suitability}

System suitability parameters are considered as an important part in analytical method development and validation. They ensure the optimal performance of the system. Chromatographic parameters viz., number of theoretical plates $(N)$, retention time $\left(R_{t}\right)$, resolution $\left(R_{s}\right)$, and peak asymmetric factor $(A)$ were monitored after six replicate injections of the standard Rilpivirine HCL at a concentration of $100 \mu \mathrm{g} / \mathrm{ml}$.

\section{RESULT AND DISCUSSION}

\section{Method development}

The chromatographic conditions for the present method were optimized based on various trial experiments carried out by modifying the mobile phase composition, mobile phase ratio, $\mathrm{pH}$, and column utilized to achieve symmetric analyte peak and short runtime. Acetonitrile was used as an organic modifier in the mobile phase. Initial separations were carried out using acetonitrile and water as mobile phase at different ratios which showed peak asymmetry. Then, the aqueous phase was replaced with LC-MS/MS compatible buffers. Finally, a symmetrical analyte peak with short run time was achieved with acetonitrile and $0.05 \mathrm{M}$ ammonium acetate buffer $(3.5 \mathrm{pH}$ adjusted with glacial acetic acid) with a mobile phase ratio of $40: 60 \mathrm{v} / \mathrm{v}$ at a 


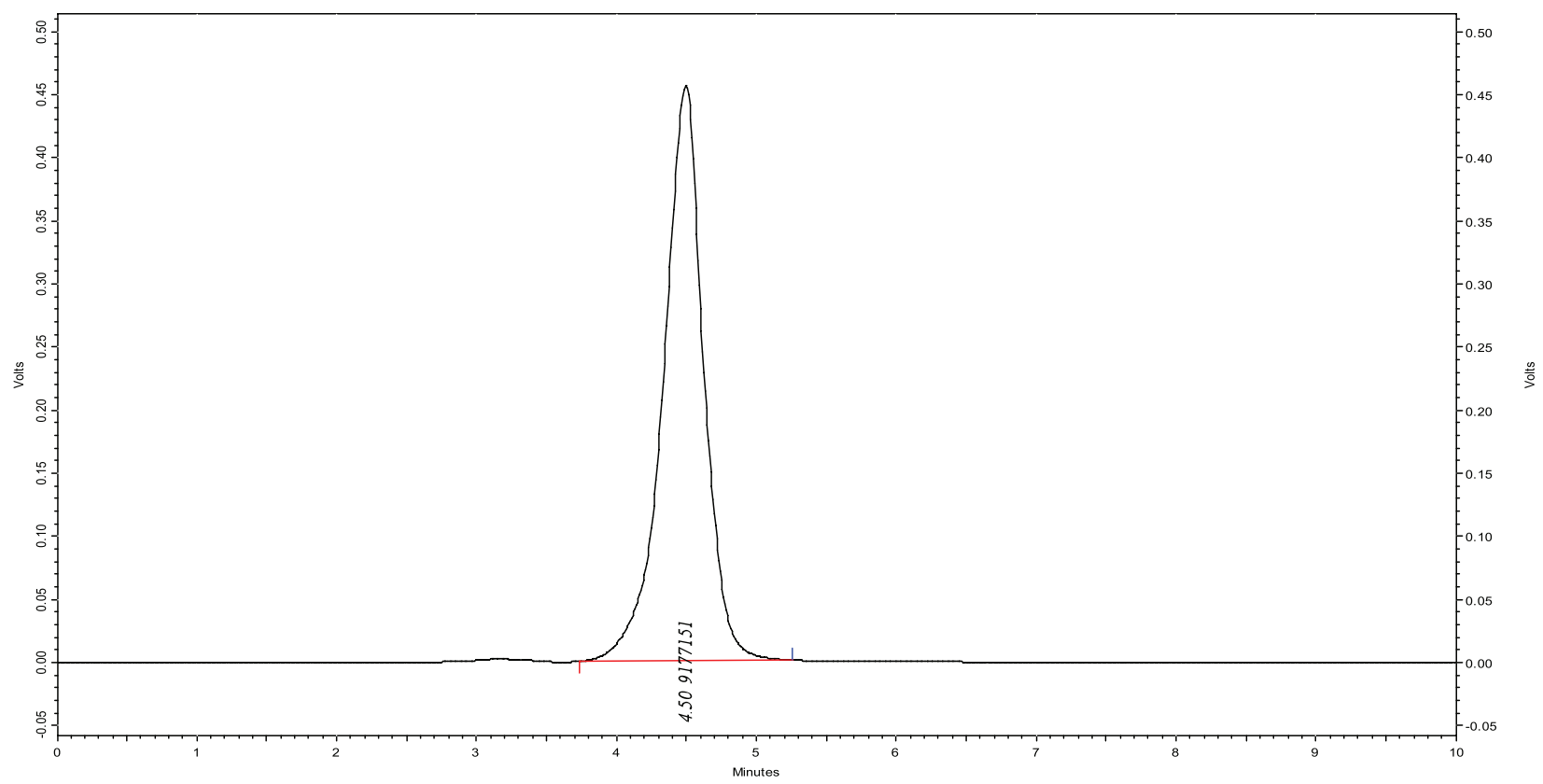

Figure 3. Typical chromatogram of the standard solution (Rilpivirine hydrochloride $-10 \mu \mathrm{g} / \mathrm{ml}$ ).

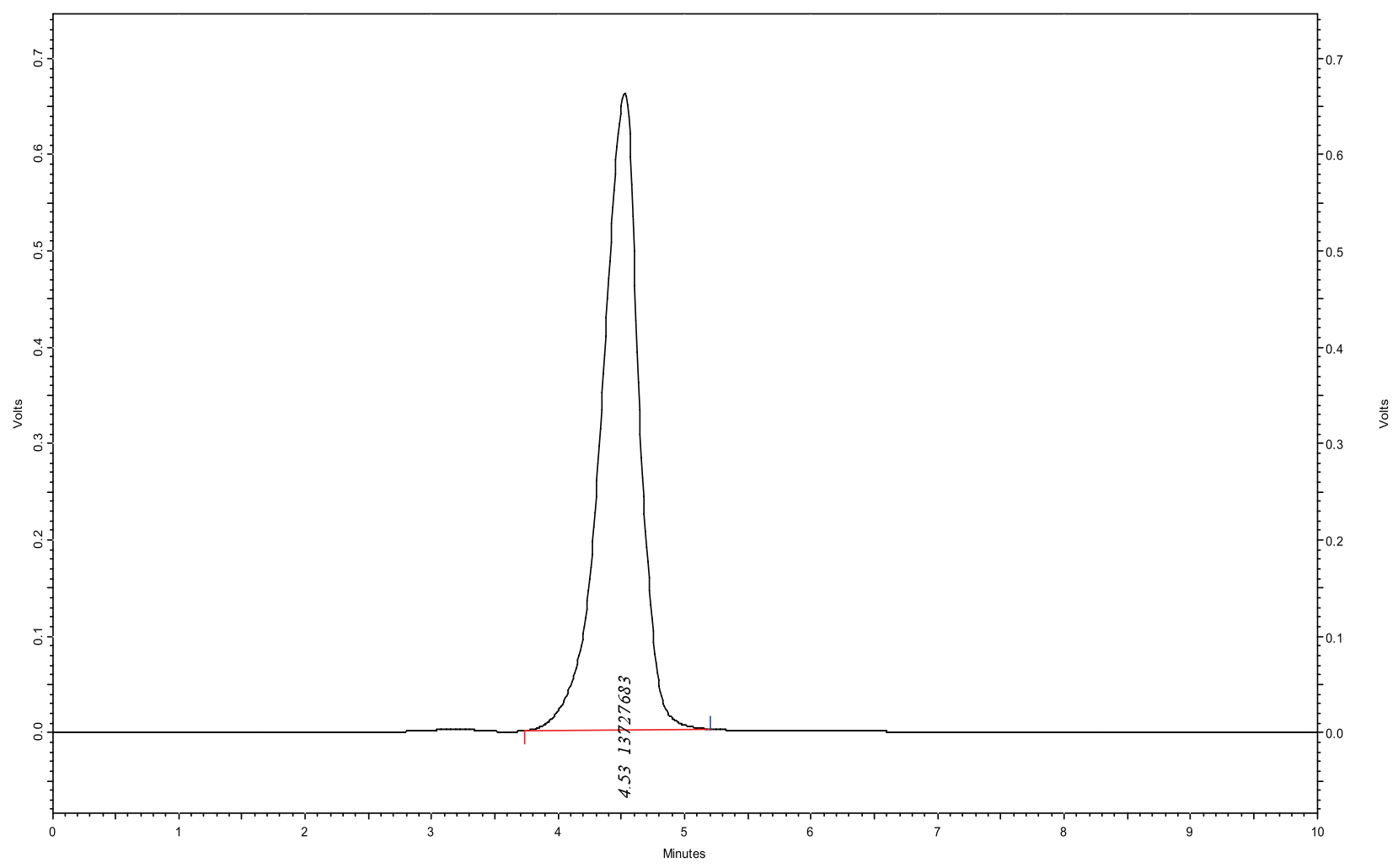

Figure 4. Typical chromatogram of the sample solution extracted from tablet dosage form.

flow rate of $0.8 \mathrm{ml} /$ minutes. The stationary phase used was shim pack $\mathrm{C}_{18}$ column, $(150 \times 4.6 \mathrm{~mm} ; 5 \mu)$ and the eluents were monitored at $291 \mathrm{~nm}$. The Rilpivirine hydrochloride eluted at $4.50 \pm 0.05$ minutes. The solvents used for the preparation of the mobile phase were filtered using $0.45 \mu$ poly tetra fluoro ethylene (PTFE) membrane filter before delivering into the HPLC system. The chromatograms were recorded and processed using the class VP data station. 
Table 1. Accuracy studies of Rilpivirine hydrochloride.

\begin{tabular}{cccc}
\hline S. no & Actual concentration $(\boldsymbol{\mu g} / \mathbf{m l})$ & Recovered concentration $(\boldsymbol{\mu g} / \mathbf{m l}) \pm \mathbf{S D} ; \mathbf{\% R S D}(\boldsymbol{n}=\mathbf{3})$ & Percentage recovered $(\%)$ \\
\hline 1 & 3 & $2.96 \pm 0.0264 ; 0.2656$ & 99.60 \\
2 & 13 & $12.91 \pm 0.0964 ; 0.3224$ & 100.02 \\
3 & 45 & $43.87 \pm 0.1850 ; 0.3709$ & 99.74 \\
\hline
\end{tabular}

Table 2. Precision studies of Rilpivirine hydrochloride.

\begin{tabular}{cccc}
\hline S. no & $\begin{array}{c}\text { Concentration } \\
(\boldsymbol{\mu} \mathbf{g} / \mathbf{m l})\end{array}$ & $\begin{array}{c}\text { Intraday } \\
\text { mean } \pm \text { SD; \%RSD }(\boldsymbol{n}=\mathbf{6})\end{array}$ & $\begin{array}{c}\text { Interday } \\
\text { mean } \pm \text { SD; \%RSD }(\boldsymbol{n}=\mathbf{6})\end{array}$ \\
\hline 1 & $3(\mathrm{LQC})$ & $15,832,062 \pm 262,291.9 ; 1.6567$ & $16,231,563 \pm 265,321.2 ; 1.5893$ \\
2 & $13(\mathrm{MQC})$ & $1,874,196 \pm 265,821.86 ; 1.4183$ & $15,386,220 \pm 268,331.6 ; 1.6479$ \\
3 & $45(\mathrm{HQC})$ & $13,934,412 \pm 229,750.5 ; 1.6487$ & $14,843,321 \pm 253,277.5 ; 1.6274$ \\
\hline
\end{tabular}

$\mathrm{LQC}=$ low quality control, $\mathrm{MQC}=$ middle quality control, $\mathrm{HQC}=$ high quality control samples.

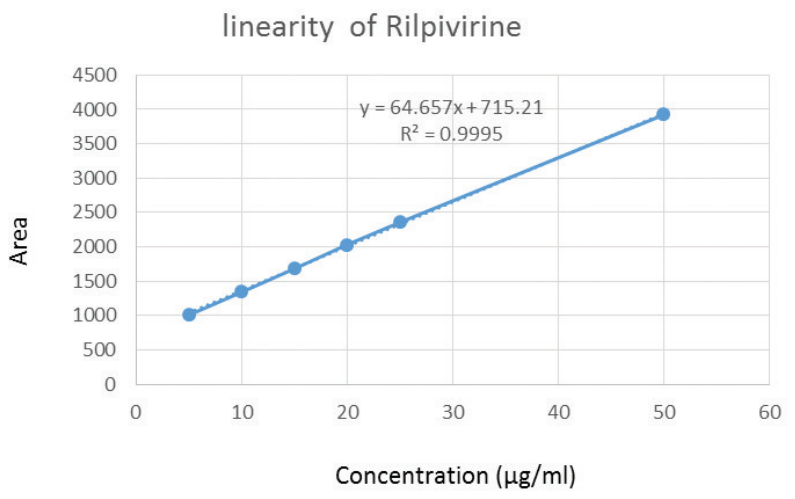

Figure 5. Linearity graph of Rilpivirine hydrochloride.

Table 3. System suitability parameters.

\begin{tabular}{ccc}
\hline Sr. no & Parameters & Rilpivirine hydrochloride \\
\hline 1 & Retention time (minutes) & 4.5 minutes \\
2 & Theoretical plates $(N)$ & 2,917 \\
3 & Tailing factor & 0.9 \\
4 & Asymmetry factor $(A)$ & 0.8 \\
5 & Regression coefficient $\left(R^{2}\right)$ & 0.9995 \\
6 & Regression equation & $Y=64.657 x+715.21$ \\
7 & Linearity and range & $10-50 \mu \mathrm{g} / \mathrm{ml}$ \\
8 & Detection limit (LOD) & $0.104 \mu \mathrm{g} / \mathrm{ml}$ \\
9 & Quantification limit (LOQ) & $0.315 \mu \mathrm{g} / \mathrm{ml}$ \\
\hline
\end{tabular}

\section{Method validation}

\section{Specificity/selectivity}

The method specificity was demonstrated by injecting the diluents, standard solution of Rilpivirine hydrochloride, and the sample solution extracted from the tablet formulation for any coeluting peaks at the retention time of the drug $(4.50$ \pm 0.05 minutes). There were no coeluting peaks, the peak shape was symmetric and sharp indicating the specificity of the optimized chromatographic method. The chromatograms of the standard and sample solution are depicted in Figures 3 and 4.
Table 4. Assay of marketed formulations.

\begin{tabular}{cccc}
\hline Sr. no & Sample & Label claim (mg) & $\begin{array}{c}\text { Amount present (mg/vial) } \pm \text { SD; } \\
\text { \%RSD }\end{array}$ \\
\hline 1 & Formulation-I & 25 & $24.89 \pm 0.1520 ; 1.9832$ \\
2 & Formulation-II & 50 & $59.89 \pm 0.1482 ; 1.6871$ \\
3 & Formulation-III & 100 & $99.89 \pm 0.1827 ; 1.6947$ \\
\hline
\end{tabular}

Accuracy and precision

The accuracy of the method was expressed as \% mean recovery for three different concentration levels $(3,13$, and 45 $\mu \mathrm{g} / \mathrm{ml}$ ) by the standard addition method. Triplicate analysis was performed at each level. Percent mean recovery was calculated. The accuracy of the developed method was between $98 \%$ and $102 \%$ (Table 1). The developed method was also used for the assay of the marketed Rilpivirine HCL tablet formulation. The results obtained were comparable to that of the label claim and is tabulated in (Table 4).

The intraday and interday precision studies carried out showed a $\%$ RSD, $<2 \%$, which is of indication of the precision of the method (Table 2).

\section{Linearity}

The calibration curve was plotted for six different concentrations of drug vs. corresponding peak area. Excellent correlation between the concentrations and peak area were observed within the concentration range of $(5-50 \mu \mathrm{g} / \mathrm{ml})$ for the drug. The correlation coefficient of Rilpivirine is $\geq 0.999$, the slope and the intercept were found to be 64.657 and 715.21, respectively. The linearity graph is represented in Figure 5.

\section{Detection limit and quantification limit}

The detection and quantification limit represent the sensitivity of the proposed method. The LOD and LOQ were found to be 0.104 and $0.315 \mu \mathrm{g} / \mathrm{ml}$, respectively, indicating the sensitivity of the method.

\section{System suitability}

The system suitability was carried out by performing the experiments and observing the changes in separation, retention time, and asymmetry of the peaks with six replicate injections of the standard at the working concentration. The results of 
Table 5. Robustness results.

\begin{tabular}{cccc}
\hline Sr. no. & Parameters & & Retention time \\
\hline \multirow{2}{*}{1} & Mobile phase ratio & $60: 40$ & $4.50 \pm 0.2$ \\
& & $50: 50$ & $5.21 \pm 0.2$ \\
& & $65: 45$ & $4.7 \pm 0.2$ \\
2 & (acetonitrile: buffer) & 3.5 & $4.7 \pm 0.2$ \\
& & 4 & $4.62 \pm 0.2$ \\
& & 4.5 & $5.1 \pm 0.2$ \\
3 & Flow rate & 0.8 & $4.6 \pm 0.2$ \\
& & 1 & $4.8 \pm 0.2$ \\
\hline
\end{tabular}

system suitability were found to be within the limits which are summarized in Table 3.

\section{Robustness and ruggedness}

Robustness of the method was carried out by altering the flow rate $( \pm 0.1 \mathrm{ml} /$ minutes $), \mathrm{pH}( \pm 0.2)$, column temperature $\left( \pm 2^{\circ} \mathrm{C}\right)$, and organic phase composition $( \pm 2 \%)$ variations (Table 5).

No significant changes in the chromatographic parameters were observed with change in the experimental conditions proving that the developed method was robust (Table 5).

A rapid, simple, and sensitive RP HPLC method was developed for the quantification of Rilpivirine hydrochloride utilizing LC MS/MS compatible solvents with a short run time of 4.50 minutes.

\section{CONCLUSION}

A rapid, simple, sensitive, precise, and accurate RP HPLC method was developed and validation was carried out as per ICH guidelines. The relative standard deviation was $0.709 \%$ indicating the method precision. Rilpivirine hydrochloride showed good linearity in the concentration range of 5 and 50 $\mu \mathrm{g} / \mathrm{ml}$. The accuracy of the method was expressed by the recovery studies. The mean recovery for the present validated method ranged between $98 \%$ and $102 \%$. Thus, it may be concluded that an accurate, precise, and rapid RP HPLC method was developed and validated for the routine quantification of Rilpivirine hydrochloride in bulk and pharmaceutical formulations.

\section{ACKNOWLEDGMENTS}

The authors are thankful to Mylan laboratory, Hyderabad, India for the gift sample of Rilpivirine hydrochloride (API).

\section{REFERENCES}

Bakshi M, Shingh S. Development of validated stability indicating assay method - critical review. JPBA, 2002; 78:1011-40.

Devanaboyina N, Anusha MJ, Bharathi D, Anusha C, Srinu U, Prabhu KNVSS. Liqui chromatography method development and validation for analysis of Rilpivirine in bulk and pharmaceutical dosage form by RP HPLC. IJCNS, 2014; 2(3):104-8.

Fathima N, Reddy PR, Brahmaiah M, Qasimullah, Huq GA. Development and validation of stability indicating RP HPLC methods for determination of impurities in rilpivirine hydrochloride capsules. WJPPS, 2018; 7(1):1118-34.

International Conference on Harmonization of Technical Requirements for Registration of Pharmaceuticals for Human use. Validation of analytical procedures: text and methodology ICH Q2 (R1), 2005.

Kavitha KY, Geetha G, Hariprasad R, Venkatnarayana R, Kaviarasu M. Development and valiation of RP UPLC analutiacl method for simultaneous estimation of emtricitabine, Rilpivirine, Tenofovir Disoproxil fumarate and its pharmaceutical dosage form. IRJP, 2013; 4(1): $150-5$.

Lieven B, Gerben K, Willy D, Marc F, Alfons W, Esther B. Development of a long-acting injectable formulation with nanoparticles of Rilpivirine (TMC278) for HIV treatment. Eur J Pharma Biopharma, 2009; 72:502-8

Madhuri M, Vijaya Sri K, Jain GV. Development and validation of RP HPLC method for Rilpivirine hydrochloride in bulk and use in analysis of prepared nano suspension. Indian Drugs, 2015; 52(04): $42-6$.

Marineni B, Krishna V, Sreenivasulu Reddy T. A validated stability indicating HPLC assay method for Rilpivirine hydrochloride in buklk drug. Int J Pharm Bio Sci, 2013; 3(4):278-87.

Reddiah CV, Ramadevi P, Mukkanti K. Effective estimation of Rilpivirine by HPLC method in tablet dosage forms and its invitro dissolution assessment. IJPPS, 2012; 4(2):595-9.

Sarkar M, Sateesh K, Ramesh P. Development and validation RP-HPLC and ultraviolet spectrophotometric methods of analysis for the quantitative estimation of antiretroviral drugs in pharmaceutical dosage form. J Chromatogr B, 2006; 830:349-54.

Schrijversa R, Desimmiea B, Debysera Z. Rilpivirine: a step forward in tailored HIV treatment. J Lancet, 2011; 378:201-3.

Sharma M, Saravolatz LD. Rilpivirine: a new nonnucleoside reverse transcriptase inhibitor. J Antimicrob Chemother, 2013; 68:250-6.

Venkatesan S, Kannappan N, Mannemala SS. Stability indicating HPLC method for the simultaneous determination of HIV tablet containing Emtricitabine, Tenofovir Disoproxil Fumarate and Rilpivirine Hydrochloride in pharmaceutical dosage form. Int Sch Rese, 2014; 2014:29: 1-9.

UNAIDS. AIDS epidemic update. WHO Regional Office Europe. 2009. WHO Library cataloging

\section{How to cite this article:}

Patel S, Nagappan K, Reddy GS. A new quantitative reverse phase high-performance liquid chromatographic method for the quantification of Rilpivirine hydrochloride in bulk and dosage forms. J App Pharm Sci, 2018; 8(11): 157-162. 